\title{
Health Insurance
}

\section{The Impacts of the State Children's Health Insurance Program on Children Who Enroll: Findings from Ten States}

\section{Genevieve Kenney}

Objective. Examine the extent to which enrollment in the State Children's Health Insurance Program (SCHIP) affects access to care and service use in 10 states that account for over 60 percent of all SCHIP enrollees.

Data Sources/Study Setting. Surveys of 16,700 SCHIP enrollees were conducted in 2002 as part of a congressionally mandated study. Three domains of SCHIP enrollees were included: (1) children who were recently enrolled in SCHIP, (2) those who had been enrolled in SCHIP for 5 months or more, and (3) those who had recently disenrolled from SCHIP. Response rates varied across states and domains but were clustered between 75 and 80 percent. Five different types of indicators were examined: (1) service use; (2) unmet need; (3) parental perceptions about being able to meet their child's health care needs; (4) presence and type of a usual source of care; and (5) provider communication and accessibility.

Study Design. The experiences SCHIP enrollees have while on the program are compared with those a separate sample of children had before enrolling using a separate sample pretest and posttest design, controlling for observable characteristics of the children and their families.

Data Collection/Extraction Methods. The sample was drawn based on a list frame of SCHIP enrollees. The survey was administered in English and Spanish, by Computer-Assisted Telephone Interviewing (CATI). Field follow-up was used to locate families who could not be reached by telephone and these interviews were conducted by cellular telephone.

Principal Findings. SCHIP enrollment was found to improve access to care along a number of different dimensions, other things equal, particularly relative to being uninsured. Established SCHIP enrollees were more likely to receive office visits, preventive health and dental care, and specialty care, more likely to have a usual source for medical and dental care and to report better provider communication and accessibility, and less likely to have unmet needs, financial burdens, and parental worry associated with meeting their child's health care needs. The findings are robust with respect to alternative specifications and hold up for individual states and subgroups. 
Conclusions. Enrollment in SCHIP appears to be improving children's access to primary health care services, which in turn is causing parents to have greater peace of mind about meeting their children's needs.

Key Words. Impacts of health insurance coverage, the State Children's Health Insurance Program (SCHIP), access and use of health care

The State Children's Health Insurance Program (SCHIP) was created in 1997 primarily to expand insurance coverage to more low-income children. States had latitude over numerous aspects of their program design and ultimately all states expanded eligibility for public coverage under the new program (Kenney and Chang 2004). One of the yardsticks by which SCHIP is measured is the extent to which the program improves children's access to and receipt of care over and above what they would have experienced otherwise. SCHIP is expected to lower the costs and other barriers associated with obtaining care for the children who enroll, particularly relative to being uninsured, which should in turn, increase their access to care.

Prior research has demonstrated that uninsured children experience more access problems and receive fewer services than children with public health insurance coverage (Rosenbach 1989; Monheit and Cunningham 1992; Stoddard, St. Peter, and Newacheck 1994; Currie and Thomas 1995; Newacheck, Hughes, and Stoddard 1996; Moreno and Hoag 2001; Dubay and Kenney 2001). However, the access and use gaps found between the uninsured and the insured may derive not only from differential access to health care, but may also reflect unmeasured differences between the two groups in health seeking behavior and attitudes toward health care.

A number of studies have attempted to address the potential bias introduced when comparing the uninsured and insured, by examining changes in access and use following enrollment in a public health insurance program (Lave et al. 1998; Szilagyi et al. 2000, 2004, 2006; Slifkin et al. 2001; Damiano et al. 2002; Dick et al. 2004; Kempe et al. 2005; McBroome, Damiano, and Willard 2005; Shone et al. 2005). These studies have found improvements in access and use for children who enrolled in the program based on a longitudinal analysis of children's experiences before and after they have coverage. Two of these studies examined the impacts of non-Medicaid programs that predated the enactment of the SCHIP program: Szilagyi et al. (2000) reported

Address correspondence to Genevieve Kenney, Ph.D., The Urban Institute, 2100 M Street, NW, Washington, DC 20037. 
on Child Health Plus in New York and Lave et al. (1998) reported on the Children's Health Insurance Program in Pennsylvania while the other studies focused on SCHIP programs. All of these studies found improvements in a number of different measures of health care access and use for children who enrolled in these programs. These findings suggest that differences in service use found between the uninsured and the insured are not all driven by unmeasured differences in characteristics of the two groups, but instead reflect greater access to care afforded to children with health insurance coverage.

In this paper, the impacts of SCHIP on the children who are served by the program are examined using an approach that is a variant on that used by Lave et al. (1998), Szilagyi et al. (2000), Damiano and Williard (2002), and Dick et al. (2004). The 10 states examined-California, Colorado, Florida, Illinois, Louisiana, Missouri, New Jersey, New York, North Carolina, and Texas-include a large proportion of all low-income uninsured children in the United States, wide geographic representation, and diverse approaches to program design. These states account for over 60 percent of all SCHIP enrollees nationwide and represent all four census regions (Smith and Rousseau 2005). They reflect the three different SCHIP program structures (California, Colorado, Florida, New York, North Carolina, and Texas have separate nonMedicaid expansions, ${ }^{1}$ Louisiana and Missouri have Medicaid expansions, and Illinois and New Jersey have a combination program with Medicaid and non-Medicaid components). They also vary in terms of their reliance on managed care, their cost sharing structures, and benefit packages (Hill et al. 2005). To estimate impacts, the experience of a sample of enrollees who have been on the program for at least 5 months is contrasted with the pre-SCHIP experience of a separate sample of recent enrollees, using data from 2002. The following section describes the data and methodological approach. Subsequent sections present results and discuss the implications.

\section{DATA AND METHODOLOGICAL APPROACH}

The data for this analysis were drawn from surveys of 16,700 SCHIP enrollees fielded in 10 states in 2002. The survey was conducted in English and Spanish, by telephone using Computer-Assisted Telephone Interviewing (CATI). ${ }^{2}$ Field follow-up was used to locate families who could not be reached by telephone and cellular phones were used to conduct interviews with families that lacked landlines. Interviews were conducted with the person most knowledgeable about the health care needs and services of the sampled child. 
Data from state SCHIP eligibility and enrollment files were used to construct the sample frames for each state and program. In New Jersey and Illinois, samples were drawn from both the Medicaid and the separate components of the SCHIP program; in Louisiana and Missouri, samples were drawn from SCHIP enrollees in Medicaid; and in the six other states, samples were drawn from enrollees in the separate SCHIP program. SCHIP samples were drawn in three domains: ${ }^{3}$

- Recent enrollees - defined as children enrolled in the given program for at least 1 month, but less than 3 months at the time of sample frame construction and who had had at least 2 months without any coverage in the program in the prior period-were asked about their access and use experiences before enrolling in SCHIP.

- Established enrollees-defined as children who were enrolled in the program for 5 or more months in the program at the time of sample frame construction-were asked about their access and use experiences while enrolled in SCHIP.

- Recent disenrollees-defined as children who were disenrolled from the program at the time of sample frame construction but had been enrolled in the preceding 2 months-were asked about their access and use experiences while on SCHIP.

This analysis draws primarily on the surveys of 5,394 established enrollees and 3,106 recent enrollees who provided information on health care access and use for the appropriate reference period. A total of 2,266 cases were excluded from the recent enrollee sample because their parents did not provide access and use information that reflected their children's experiences before enrolling in SCHIP_-201 cases were born on SCHIP, 144 cases had missing information, and 1,921 cases reported their access and use information while on SCHIP, not before SCHIP. ${ }^{4}$ A total of 441 cases were excluded from the established enrollee sample because they did not provide reliable access and use information that reflected their experiences while enrolled in SCHIP-109 children were enrolled for less than six months, 112 children had been disenrolled for more than 12 months, and 220 children had missing information on variables that were critical to the analysis.

Response rates varied from state to state and across different sample domains, but were clustered between 75 and 80 percent (Trenholm et al. 2005). As samples were selected using complex multistage procedures, sampling weights 
were developed to reflect the various stages of sampling and standard errors were calculated based on the Taylor series linearization approach.

The approach for assessing the impacts of SCHIP draws on an economic model in which the price of health inputs and services, family income and preferences, and health endowments are hypothesized to affect health services use and access to care among children (Grossman 1972; Garber and Phelps 1997; Kaestner 1999). The presence and nature of health insurance coverage, which affects the price of health care services, is the key variable in this model. SCHIP programs have broad benefit packages that are tailored to meet the needs of children and require fairly modest out-of-pocket payments for services. Thus, relative to being uninsured, SCHIP should lower the out-of-pocket costs associated with obtaining health services, which should, in turn, increase the receipt of services and reduce both unmet needs and financial burdens. SCHIP may also lead to improvements in access and use among children who would have been privately insured in the absence of SCHIP because benefit packages tend to be richer and cost sharing tends to be lower under SCHIP than for many types of private coverage (Fox, Levtov, and McManus 2003; Trude 2004).

Cross-sections of recent and established enrollees are used to estimate the impacts of SCHIP on children who enroll in the program. This quasiexperimental approach uses a separate sample pretest and posttest design (Campbell and Stanley 1963; Singleton, Straits, and Straits 1993). The experience of established enrollees (i.e., children who have been enrolled in the program for at least 5 months) - the treatment group-is compared with the pre-SCHIP experiences of newly enrolling children-the comparison group. Thus, the pre-SCHIP experiences of the recent enrollee sample serve as a counterfactual for the SCHIP experiences of the established enrollee sample. As described below, in an attempt to minimize the differences between the comparison and the treatment group, the analysis controls for other potentially confounding factors related to the characteristics of the child and their parents. In addition, numerous alternative model specifications are estimated to assess the robustness of the impact estimates.

Five different types of indicators are examined: (1) service use; (2) unmet need; (3) attitudes and stress; (4) presence and type of a usual source of care; and (5) provider communication and accessibility. These outcomes were chosen to portray a broad range of different aspects of access and use that could be affected by enrollment in SCHIP coverage, including the health care services received by the child, the worry and financial burdens parents experience related to meeting their child's health care needs, and provider 
accessibility. It is expected that children covered by SCHIP will (1) receive preventive services at higher rates; (2) experience fewer unmet needs; and (3) be more likely to have a usual source of care and to have improved provider accessibility and communication. It is also expected that their parents will have fewer concerns and financial burdens associated with meeting their child's needs and that the setting of care could shift away from clinics and health centers toward private physician's offices. The effects of SCHIP enrollment on visits to emergency rooms and hospital stays are not clear a priori.

The control variables in the multivariate models include (1) the child's age, sex, and race/ethnicity interacted with the interview language; (2) the health status of the child (i.e., general health status and presence of elevated health care needs); ${ }^{5}$ (3) household income (defined as income as a percentage of the federal poverty level) and size (the number of children in the household); (4) the educational attainment and work status of the parents; and (5) the parent's attitudes regarding the efficacy of medical care (which is defined as the extent to which the parent believes that he/she can overcome most illness without help from a doctor and that home remedies are often better than prescribed drugs); and (6) the child's county of residence.

In addition to estimating models that compare differences in access and use between all established and recent enrollees, separate estimates are presented for recent enrollees who were uninsured for all 6 months preceding their enrollment in SCHIP and for those who were covered for some or all of the 6 months preceding their enrollment in SCHIP. ${ }^{6}$ Larger differentials are expected between recent enrollees who had been uninsured for all 6 months before enrolling in SCHIP and established enrollees than between recent enrollees who had coverage for some or all of the period before enrolling, because uninsured children face much greater out-of-pocket costs when they try to obtain health services.

\section{Analytic Challenges}

There are a number of threats to the validity of the impact estimates that we derive from these models. The most fundamental concern is that the preSCHIP experiences of the recent enrollees may not serve as a reliable counterfactual for the experiences of established enrollees because of differences between the two samples. This issue is addressed by conducting a number of sensitivity analyses to assess the robustness of the findings. To address possible unobserved differences between recent and established enrollees, models are estimated just with recent enrollees who stay enrolled in the program for at 
least 5 months and we subset the established enrollee sample to those who were enrolled in SCHIP closer to the time period during which children in the recent enrollee sample were entering SCHIP. To make the recent and established enrollee samples as homogeneous as possible, we use the information on the presence of insurance coverage just before enrolling in SCHIP for both established and recent enrollees, estimating one set of impacts just for recent and established enrollees who were uninsured just before enrolling in SCHIP and another set for recent and established enrollees who were insured just before enrolling. An additional concern is that the access and use experiences children have just before enrolling may not reflect what these children typically face, as they may have atypically high service needs, which, in turn, trigger their enrollment into SCHIP. To address this possibility, children who had an emergency room visit (a hospital stay) or unmet health needs before enrollment were excluded from the analysis to assess the extent to which the impact estimates for the other outcomes are sensitive to these exclusions. Finally, we address the concern that the experiences of established enrollees may overstate the access to care that children typically have under SCHIP. As other analysis (Kenney et al. 2005) suggests that disenrollees might have had slightly worse access and use experiences with SCHIP coverage relative to the established enrollees, an additional set of SCHIP impacts were estimated using disenrollees as the treatment group in place of established SCHIP enrollees. Alternative models are also estimated that replace the county fixed effects with dummy variables for the child's state of residence and whether the child lives in a county that is in a metropolitan statistical area (MSA).

In addition to estimating state-specific models and the alternative specifications outlined above, separate models were also estimated for a number of key subgroups to assess the extent to which the findings held up for different types of children. Separate impact estimates were derived for children in different subgroups defined by their race/ethnicity, their age, their health status, and their parent's educational attainment. In addition, interaction terms were added to test whether SCHIP impacts appeared to vary with the characteristics of the child and his/her family. Models were estimated on recent and established enrollees who had been uninsured just before enrolling in SCHIP that included all the demographic and socioeconomic control variables from the core model, a dummy variable for whether the child was a recent or established enrollee, and a set of terms that interacted that dummy variable with the child's health status, age, and race/ethnicity/ primary language, the parent's educational attainment, and the child's state of residence. 


\section{RESULTS}

\section{Characteristics of Recent and Established Enrollees}

With few exceptions, notably age and state of residence, children in the established enrollee sample closely resemble the children in the recent enrollee sample (Table 1). The characteristics of the recent enrollee sample are quite similar to those of the established enrollee sample with respect to the race and ethnic background of the child, the characteristics of the parents, and the structure of the household. For example, 43 percent of both the recent and the established enrollee samples live in households with more than two children. Likewise, 36 percent of the recent enrollee sample came from a one-parent household compared with 35 percent of the established enrollee sample.

On average, the children in the established enrollee sample are older than the children in the recent enrollee sample, which is likely due in part to the fact that many established SCHIP enrollees have been enrolled in the program for a number of years (e.g., more than half of all children in the established enrollee sample had been enrolled in SCHIP for 2 years or more). For example, 31 percent of the children in the recent enrollee sample are under six compared with 19 percent of the children in the established enrollee sample. Proportionately more children in the established enrollee sample are in the 6-12 and the over 13 age groups: 48 and 32 percent of the established enrollee sample, respectively, compared with 45 and 24 percent of the recent enrollee sample. The distribution of children in the recent and established enrollee samples also varies across states, with proportionately more children in the recent enrollee sample from Texas (33 percent) compared with 26 percent in the established enrollee sample and fewer in the recent enrollee sample from New York (4 percent) compared with 13 percent in the established enrollee sample. The different state-specific distributions of the recent and the established enrollee samples maybe due in part to the different levels of maturity of the 10 SCHIP programs: The New York program predates SCHIP whereas the separate SCHIP program was implemented in Texas in 2000, 3 years after Title XXI was enacted (Hill, Hawkes, and Harrington 2003). Finally, the children in the recent enrollee sample are about five percentage points more likely to have parents that attended college compared with the children in the established enrollee sample.

\section{Differences in Outcomes between Recent and Established Enrollees}

Table 2 shows the mean values of the different access and use outcomes for both established enrollees and recent enrollees, according to their coverage 
Table 1: Selected Characteristics of Recent and Established SCHIP Enrollees and Their Parents

\begin{tabular}{|c|c|c|}
\hline & $\begin{array}{c}\text { Recent } \\
\text { Enrollees (\%) }\end{array}$ & $\begin{array}{c}\text { Established } \\
\text { Enrollees (\%) }\end{array}$ \\
\hline \multicolumn{3}{|l|}{ State } \\
\hline California & 28.9 & 28.6 \\
\hline Colorado & $3.7^{* * *}$ & 1.8 \\
\hline Florida & 12.3 & 13.3 \\
\hline Illinois & $3.9^{* * *}$ & 2.4 \\
\hline Louisiana & 3.1 & 3.4 \\
\hline Missouri & $1.8^{* * *}$ & 3.7 \\
\hline New Jersey & 4.4 & 4.8 \\
\hline New York & $4.4^{* * *}$ & 13.3 \\
\hline North Carolina & $4.5^{* *}$ & 3.0 \\
\hline Texas & $32.9^{* * *}$ & 25.9 \\
\hline \multicolumn{3}{|l|}{ Age of child (in years) } \\
\hline $0-5$ & $31.1^{* *}$ & 19.3 \\
\hline $6-12$ & $44.5^{*}$ & 48.3 \\
\hline 13 and older & $24.4^{* * *}$ & 32.4 \\
\hline \multicolumn{3}{|l|}{ Race, ethnicity, and language } \\
\hline White, non-Hispanic, primary language is English & 28.1 & 30.2 \\
\hline Hispanics, primary language is English & 20.6 & 20.1 \\
\hline Hispanics, primary language is Spanish & 29.7 & 27.7 \\
\hline Black, non-Hispanic, primary language is English & 10.8 & 10.6 \\
\hline Other, non-Hispanic, primary language is English & 4.2 & 4.0 \\
\hline Non-Hispanic, primary language is not English & 4.2 & 4.4 \\
\hline Missing race, ethnicity, or language & 2.3 & 2.9 \\
\hline Female & 47.9 & 46.8 \\
\hline Child has elevated health care needs & 22.5 & 24.1 \\
\hline \multicolumn{3}{|l|}{ Household income, by FPL range } \\
\hline$<150 \%$ of the FPL & 65.2 & 63.3 \\
\hline $150-199 \%$ of the FPL & 19.5 & 21.3 \\
\hline $200 \%$ or higher of the FPL & 9.3 & 8.5 \\
\hline Missing & 6.0 & 7.0 \\
\hline \multicolumn{3}{|l|}{ Parents' employment status } \\
\hline Has one parent and the parent worked & 30.2 & 30.7 \\
\hline Has one parent and the parent did not work & 5.4 & 4.3 \\
\hline Two parents and neither worked & 2.1 & 2.9 \\
\hline Two parents and one worked & 32.9 & 33.3 \\
\hline Two parents and both worked & 29.4 & 28.8 \\
\hline \multicolumn{3}{|l|}{ Number of children in the household } \\
\hline One & 19.9 & 18.3 \\
\hline Two & 37.6 & 38.3 \\
\hline More than two & 42.5 & 42.9 \\
\hline \multicolumn{3}{|l|}{ Education } \\
\hline Less than high school & $21.3^{*}$ & 24.5 \\
\hline High school diploma or GED & 32.7 & 34.5 \\
\hline Some college or higher & $46.0^{* * *}$ & 40.6 \\
\hline
\end{tabular}


Table 1: Continued

\begin{tabular}{lcc}
\hline & $\begin{array}{c}\text { Recent } \\
\text { Enrollees (\%) }\end{array}$ & $\begin{array}{c}\text { Established } \\
\text { Enrollees (\%) }\end{array}$ \\
\hline $\begin{array}{l}\text { Health efficacy } \\
\quad \begin{array}{l}\text { Parent reports that he or she can overcome most } \\
\text { illness without help from a doctor }\end{array}\end{array}$ & 55.0 & 56.7 \\
$\quad \begin{array}{l}\text { Parent believes home remedies are often better } \\
\text { than prescribed drugs }\end{array}$ & 33.2 & 32.9 \\
\begin{tabular}{l} 
Number \\
\hline
\end{tabular} & 3,106 & 5,394 \\
\hline
\end{tabular}

Source: 2002 congressionally mandated survey of SCHIP enrollees and disenrollees in 10 states. Note: All variables refer to the six months before the interview.

FPL, federal poverty level; SCHIP, State Children's Health Insurance Program.

$* p$-value difference between recent and established enrollees <.05.

*** $p$-value difference between recent and established enrollees $<.01$.

status before enrolling in the program. ${ }^{7}$ Established enrollees enjoy greater access to care and their parents have fewer concerns about addressing their children's health care needs relative to the experiences parents and their children had before enrolling, particularly relative to recent enrollees who had been uninsured in the 6 months before enrolling. The areas where the differences are most pronounced are unmet needs, parents' attitudes about their ability to meet the child's health care needs, and the presence of a usual source for dental care. The following section presents differences between the established and recent enrollee samples based on multivariate models that control for a number of different characteristics of the children and their families.

\section{Multivariate Estimates of SCHIP Impacts on Access and Use}

Established SCHIP enrollees generally had better access and use experiences on SCHIP than recent enrollees had before enrolling in the program, other things being equal (Table 3). ${ }^{8}$ Overall, established enrollees fared better than recent enrollees on about two-thirds of the outcomes that were examined. Relative to the experiences children had before enrolling in SCHIP, established enrollees were more likely to receive preventive dental care and less likely to have emergency room visits; less likely to have unmet needs for physician services, prescription drugs, dental care, specialty care, and hospital care; and less likely to have one or more unmet need; more likely to have parents who have confidence in their ability to meet their child's health care needs; less likely to have parents who say that meeting their child's needs 
Table 2: Bivariate Means on Access and Use Measures for Recent and Established SCHIP Enrollees

\begin{tabular}{|c|c|c|c|c|}
\hline & \multirow[b]{2}{*}{ Established $^{\dagger}$} & \multicolumn{3}{|c|}{ Recent Enrollees } \\
\hline & & All & $\begin{array}{l}\text { Uninsured } \\
\text { All } 6 \text { Months }\end{array}$ & Insured $^{\ddagger}$ \\
\hline \multicolumn{5}{|l|}{ Service use based on parent's report } \\
\hline Any doctor/other health professional visit & 66.7 & 67.6 & $58.4^{* *}$ & $76.7^{* * *}$ \\
\hline Any preventive care of checkup visit & 45.4 & 45.5 & $32.6^{* * *}$ & $58.2^{* * *}$ \\
\hline Any dental visit for checkup/cleaning ${ }^{\S}$ & 57.3 & $44.0^{* * *}$ & $31.3^{* *}$ & 58.2 \\
\hline Any specialist visit & 16.7 & 14.7 & $12.4^{*}$ & 17 \\
\hline Any mental health visit & 5.4 & 4.2 & $3.7^{*}$ & 4.8 \\
\hline Any specialist or mental health visit & 20.3 & 18.1 & $15.3^{* *}$ & 21 \\
\hline Any emergency room visit & 18.0 & $27.6^{* * *}$ & $24^{*}$ & $31.2^{* * *}$ \\
\hline Any hospital stay & 3.7 & 4.8 & 3.4 & $6.3^{*}$ \\
\hline \multicolumn{5}{|l|}{ Unmet needs based on parent's assessment } \\
\hline Doctor/health professional care & 2.1 & $6.6^{* * *}$ & $9.1^{* * *}$ & $4.3^{* * *}$ \\
\hline Prescription drugs & 4.1 & $8.1^{* *}$ & $10.6^{* *}$ & 5.8 \\
\hline Specialists & 3.4 & $7.0^{* * * * *}$ & $9.3^{* *}$ & 4.9 \\
\hline Hospital care & 1.4 & $5.5^{* *}$ & $7.6^{* * *}$ & $3.6^{* * *}$ \\
\hline Any unmet needs (excluding dental care) & 9.2 & $17.8^{* * *}$ & $21.4^{* *}$ & $14.5^{\text {*** }}$ \\
\hline Dental care $\$$ & 11.9 & $19.1^{* *}$ & $22.8^{* *}$ & $15.2^{*}$ \\
\hline Any unmet needs (including dental care) $)^{\S}$ & 18.3 & $27.6^{* * *}$ & $33^{* *}$ & $22.6^{*}$ \\
\hline More than one unmet need & 3.3 & $9.8^{* *}$ & $13.7^{* * *}$ & $6.2^{* * *}$ \\
\hline \multicolumn{5}{|l|}{ Parental perceptions about meeting child's needs } \\
\hline Very confident could get needed health care for child & 81.2 & $48.6^{* * *}$ & $37.6^{* * *}$ & $58.7^{* * *}$ \\
\hline $\begin{array}{l}\text { Never or not very often stressed about meeting } \\
\text { child's health care needs }\end{array}$ & 78.4 & $50.1^{* * *}$ & $36.5^{* *}$ & $63.1^{* * *}$ \\
\hline $\begin{array}{l}\text { Never or rarely worried about meeting child's } \\
\text { health care needs }\end{array}$ & 55.2 & $29.0^{* * *}$ & $17.9^{* * *}$ & $39.7^{* * *}$ \\
\hline $\begin{array}{l}\text { Meeting child's health care needs never of } \\
\text { rarely causes financial difficulties }\end{array}$ & 83.4 & $52.1^{* *}$ & $42.4^{* * *}$ & $61.1^{* * *}$ \\
\hline \multicolumn{5}{|l|}{ Usual source of care (USC) based on parent's report } \\
\hline Had USC in past six months & 91.4 & $80.4^{* * *}$ & $70.4^{* *}$ & 90.6 \\
\hline USC type: private doctor's office/group practice & 64.4 & $59.3^{* * *}$ & $45.2^{* *}$ & 65.9 \\
\hline Usually saw same provider at USC & 72.3 & $61.4^{* *}$ & $47.8^{* *}$ & 74.8 \\
\hline Had USC for dental care in past six months ${ }^{\S}$ & 81.3 & $59.1^{* * *}$ & $49.1^{* *}$ & $70.2^{* * *}$ \\
\hline \multicolumn{5}{|c|}{ Provider communication and accessibility based on parent's report } \\
\hline Would recommend USC & 91.7 & 91.2 & 89.2 & 92.6 \\
\hline Could reach doctor after hours & 75.6 & $68.3^{* * *}$ & $57.5^{* * *}$ & 76.3 \\
\hline Providers explain in understandable ways & 89.4 & 86.9 & $81.7 * *$ & 90.4 \\
\hline Provider treats with courtesy/respect & 93.8 & 93.3 & 91.3 & 94.6 \\
\hline Provider talks about how child feeling & 85.5 & 83.4 & $79.5^{* * *}$ & 86.1 \\
\hline Rated ease of getting care excellent or very good & 43.3 & $34.5^{* *}$ & $24.8^{* *}$ & 41.1 \\
\hline Wait time for care less than 30 minutes & 51.8 & $48.1^{*}$ & $40 * *$ & 54.6 \\
\hline Travel time to USC less than 30 minutes & 84.1 & $79.5 * *$ & $75.9^{* * *}$ & 82.3 \\
\hline Number & 5,394 & 3,106 & 1,492 & 1,583 \\
\hline
\end{tabular}

Source: 2002 congressionally mandated survey of SCHIP enrollees and disenrollees in 10 states.

Note: Estimates based on samples of recent and established SCHIP enrollees.

SCHIP, State Children's Health Insurance Program.

†"Established" is the reference category for tests of significance.

${ }^{\ddagger}$ Includes those insured some or all of the past 6 months before enrolling.

Applies to children age 3 and older.

$* p$-value $<.05$.

$* * p$-value $<.01$. 


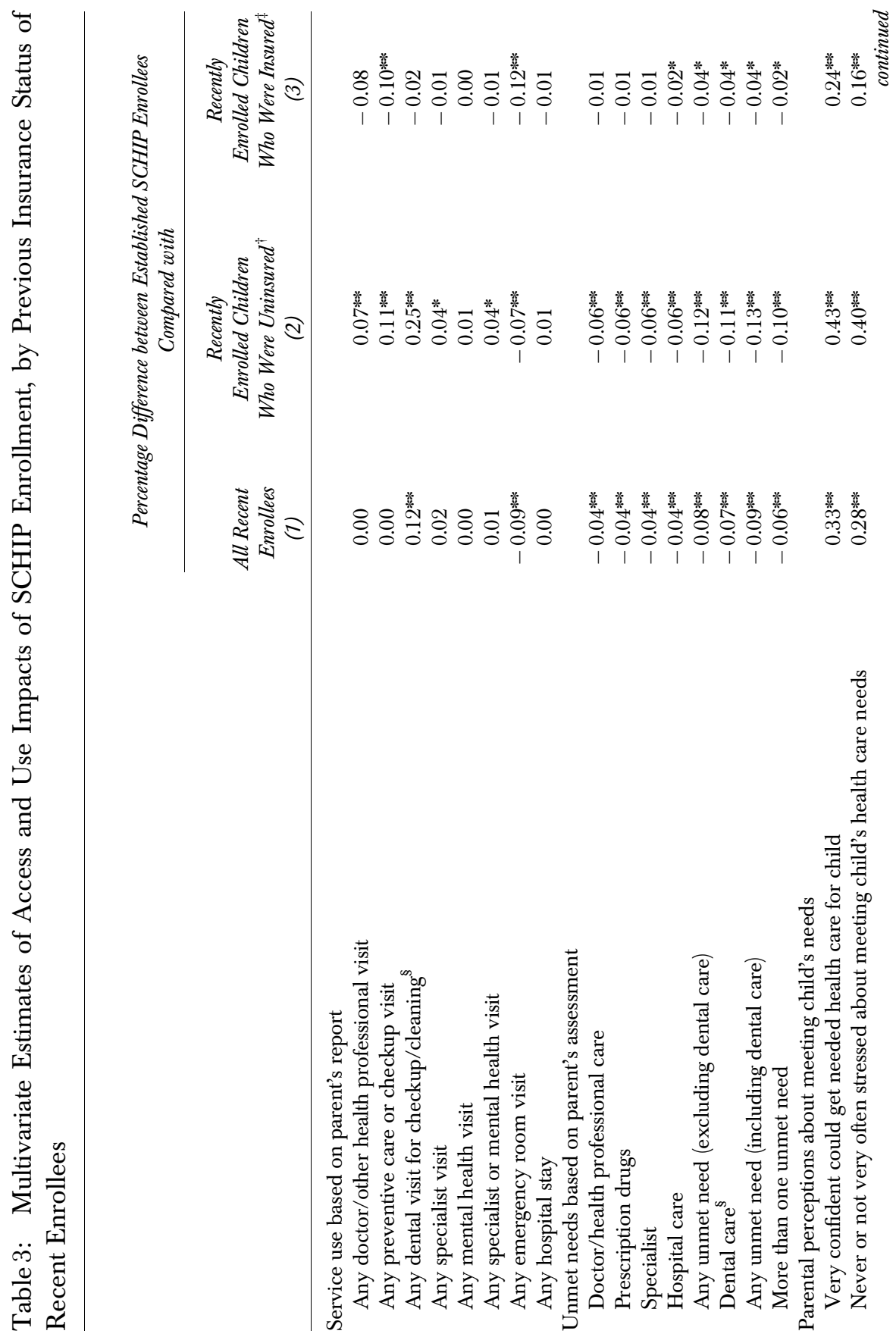


1532 HSR: Health Services Research 42:4 (August 2007)

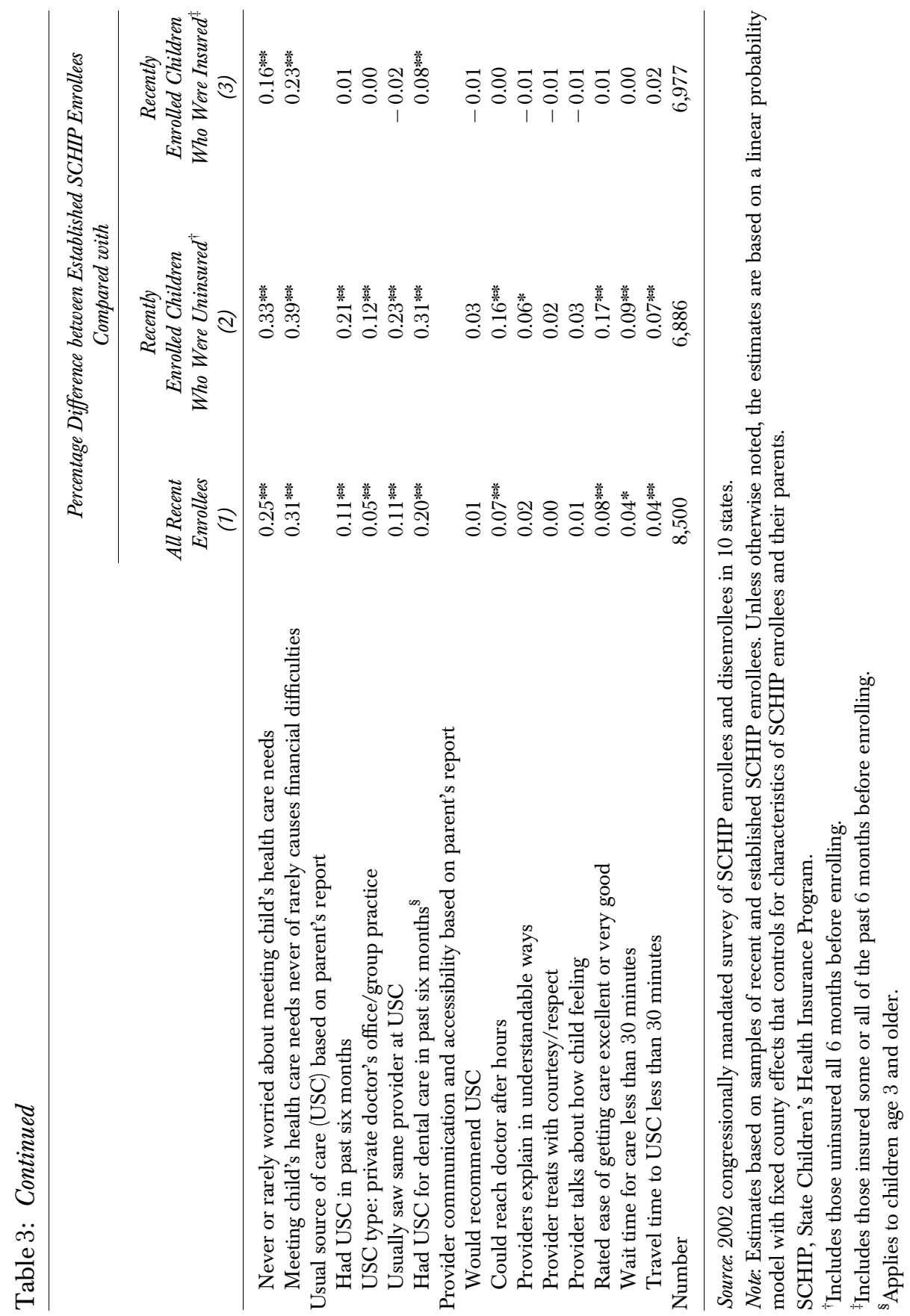


causes stress, financial burden, or worry; more likely to have a usual source for medical care, to see the same provider when they go for care and to have a usual source for dental care; more likely to rely on a private physician or group practice than a clinic or health center; and more likely to rate the care they receive as excellent, to have providers they can reach after hours, to have short waits (of 30 minutes or less) when they go for appointments and short travel times (of 30 minutes or less).

As expected, much stronger differences are found when contrasting the experiences of established SCHIP enrollees to the pre-SCHIP experiences of children who had been uninsured for at least 6 months before enrolling in SCHIP (Table 3). Not only are more of the differences statistically significant than in the general model, but also the magnitude of the differences is also substantially larger. For example, other things equal, relative to the pre-SCHIP experiences of recent enrollees who had been uninsured before enrolling in SCHIP, established enrollees are 12 percentage points more likely to have received a dental checkup compared with experiences of all recent enrollees before enrolling; in contrast, established enrollees were 25 percentage points more likely to have received a dental checkup compared with recent enrollees who had been uninsured before enrolling.

Established enrollees are more likely than those who had been uninsured during the 6 months before enrolling to receive any office visits, any preventive/well child visits, any preventive dental care, and care from a specialist and they are less likely to have emergency room visits. Established enrollees are 13 percentage points less likely than the uninsured to have any type of unmet health need and 10 percentage points less likely to have multiple unmet needs. They are also less likely to have unmet needs for physician services, prescription drugs, dental care, specialty care, and hospital care. Established enrollees are 43 percentage points more likely than the uninsured to have parents who feel very confident about their ability to address their child's health care needs and are less likely to have parents who feel stress, worry, or financial burden associated with meeting their child's needs. Established enrollees are 21 and 31 percentage points more likely than the uninsured to have a usual source of care for medical and dental care, respectively. They are also more likely to see the same provider at their usual source of care, to rely on private physician's office as a usual source of care, to rate the ease of getting care as excellent; to say that providers explained things in a way that could be understood, to be able to reach the provider after hours, and to have shorter waits when they go for appointments. 
Established enrollees appear to be doing better relative to the experiences of recent enrollees who had coverage for some or all of the 6 months before enrolling in SCHIP with respect to the measures related to unmet need, their parents' attitudes about being able to meet the child's health care needs, and having a usual source for dental care (Table 3). The results regarding service use are more mixed: established enrollees are less likely to have received a checkup and to have received any type of office visit relative to those who had coverage in the period before enrolling, but they are also less likely to have had an emergency room visit.

The impacts of enrollment are greatest relative to the children who were uninsured for the full 6 -month period before enrolling. For example, children who were uninsured for the 6 months leading up to their SCHIP enrollment are 31 percentage points less likely than the established enrollees to have a usual source for dental care, whereas those who had had coverage for some or all of the 6 months prior are just eight percentage points less likely to have a usual source for dental care. Likewise, established enrollees are 25 percentage points more likely to have received a preventive dental visit relative to children who had been uninsured all 6 months, whereas there is no statistically significant difference in receipt of preventive dental visits between established enrollees and recent enrollees who were insured for some or all of the 6 months before enrolling. When we subset the recent enrollees to those who had private coverage for all 6 months before enrolling, we see similar patterns, but fewer differences (data not shown). ${ }^{9}$

Similar patterns were found with respect to impacts when separate multivariate models were estimated for each state (Table A1, available on the HSR website). In terms of specific outcomes for models with all recent enrollees, five or more states had a statistically significant impact estimate for each individual type of unmet need; all 10 states had statistically significant impact estimates on the proportion with more than one unmet need; all 10 states had them on all four of the outcomes that reflect confidence, stress, worry and financial burden; and eight of the 10 states had them in the models for usual source for health and dental care.

Likewise, the pooled findings reported for recent enrollees who had been uninsured for the 6 months before enrolling in SCHIP hold up when separate models were estimated for each state (Table A2, available on the HSR website). In all 10 states, the children who were uninsured all 6 months before enrolling were doing worse than the established enrollees in terms of any unmet need (defined for physician care, prescription drug, dental care, and hospital care) and in terms of having more than one unmet need. Their parents 
more frequently expressed negative views in terms of confidence, stress, worry, and financial burden, and they were less likely to have a usual source for dental care. In addition, nine of the 10 states had statistically significant impacts for preventive dental checkups, unmet needs for prescription drugs, usual source for health care, and usually seeing the same provider at the usual source of care. The state-specific results that compare the experiences of established enrollees with recent enrollees who had coverage for some or all of the period prior enrolling in SCHIP are also consistent with the estimates from the model that pools estimates across the 10 states (data not shown).

\section{Sensitivity Analyses}

As indicated in "Data and Methodological Approach," we examined a number of alternative specifications to assess the robustness of our impact estimates. Tables A3-A5 (available on the HSR website) show the estimated impacts under eight different formulations that subset the established and recent enrollee samples. Although these tables show results for just some of the alternative models that were estimated, they are illustrative of the findings that emerge under all the alternative models that were estimated. What is striking about the estimates provided in these three sets of tables is how similar the findings are under all of the alternative specifications compared with the core specification. Although the specific point estimates differ from equation to equation, the overall pattern of the findings is remarkably robust across the different models. In all specifications, we find statistically significant impacts on unmet needs, confidence and stress, and on having a usual source for dental care. For example, even when the disenrollee sample is used in place of the established enrollee sample to estimate SCHIP impacts relative to being uninsured, we find that children covered by SCHIP receive more preventive dental and well-child care, have fewer unmet needs, are more likely to have a usual source for both health and dental care, have greater accessibility to providers, and their families experience fewer worries and financial difficulties associated with meeting their child's health needs.

\section{Subgroup Models}

The key results persist across all the subgroups considered here, although, due in part to the variation in the sample size of each subgroup, the precision of individual impact estimates varies across subgroups as does the extent to which the estimates achieve significance at conventional levels (Table A6, available on the HSR website). Improvements in access due to SCHIP 
enrollment are found for Hispanic children (for both those whose parents were interviewed in Spanish and for those whose parents were interviewed in English), for white children, and for black children; for preschoolers, school-age children (ages 6 to 12), and for adolescents (ages 13 to 18); for children with elevated health care needs; for children who do not have elevated health care needs; and for children who have at least one parent who has completed high school and for those who do not have a parent who has completed high school.

In particular, SCHIP enrollees in each of these different subgroups had fewer unmet health needs, their parents had higher confidence and lower worry about their ability to meet their child's health care needs, and the children are reported to have greater accessibility to and better communication with providers relative to the pre-SCHIP experiences of similar children who had been uninsured before enrolling. These results also indicate that all these different groups of established SCHIP enrollees were more likely than recent enrollees who had been uninsured to receive dental checkups and, for most subgroups examined, to receive well-child care. These findings indicate that SCHIP improves access and use for children from many different types of backgrounds and with varying health care needs.

\section{Subgroup Impact Differences}

The results indicate that the estimated impact of SCHIP on unmet needs is more pronounced for children with elevated health care needs than for children who do not have elevated health needs (Table A7, available on the HSR website). It appears that children with elevated health care needs experience larger reductions in unmet need following SCHIP enrollment compared with children in better health. However, parents whose children have elevated health care needs do not report as large an increase in the ease of getting care relative to the parents whose children do not have elevated health care needs.

This analysis also suggests somewhat more positive impacts in terms of both parental perceptions of their ability to meet their children's health care needs and the presence of a usual source for health care for adolescents than for younger children. SCHIP appears to raise parental confidence in being able to meet a child's health care needs for children in all three age groups, but the increases appear even greater for adolescents than for younger childrentheir parents are even more likely to experience increased confidence, lower stress and worry, and fewer financial difficulties associated with meeting their child's health care needs. In addition, adolescents appear to experience greater increases in the extent to which they have a usual source for health care, the 
share who use a private doctor's office or group practice as their usual source of care, and the extent to which they usually saw the same provider at their usual source of care. It appears that children whose parents have less than a high school education experience somewhat smaller improvements following enrollment in SCHIP relative to children whose parents are more highly educated. In particular, children whose parents have not completed high school experience smaller increases in the receipt of specialty and specialty/mental health care, their parents experience smaller improvements in parental stress and financial difficulty associated with meeting their child's health care needs, they experience smaller increases in the extent to which they see the same provider at their usual source of care, and their parents are less likely to report increases in the extent to which their providers reportedly treat them with courtesy and respect.

\section{CONCLUSIONS}

These findings indicate that SCHIP programs are having positive impacts on the children who enroll and on their parents. SCHIP appears to be affording children greater access to the primary health care services they need, which, in turn, is causing parents to have greater peace of mind about meeting their children's health care needs. Moreover, positive impacts are found under a broad range of alternative model specifications that address potential concerns about the validity of the impact estimates. These results corroborate the findings from longitudinal studies conducted in Florida, Iowa, Kansas, New York, and North Carolina.

The fact that improvements are found, not only in the model that combines children in the 10 states, but also in the individual state-specific models suggests that the positive impacts are not limited to one state or to one type of SCHIP program. These 10 states differ along a number of different types of program characteristics (e.g., reliance on managed care and cost sharing) that could affect access and use of services. Despite these differences, positive impacts are found on many of the different outcomes measures in each of the individual state-specific models.

In addition, not only are positive SCHIP impacts found relative to being uninsured for the entire enrollee sample, but uniformly positive impacts are also found in separate subgroup models, which suggests that a broad range of enrollees enjoy benefits from enrolling in SCHIP. Positive impacts are found for children of different races and ethnicities, for children in different age 
groups, for children with different health care needs, and for children whose parents have different levels of educational attainment. Somewhat larger positive impacts were found for children with elevated health needs, for adolescents, and for those whose parents are better educated, suggesting that there maybe some scope for achieving even further improvements for some subgroups.

However, findings presented elsewhere (Kenney et al. 2005) suggest that SCHIP programs have the potential to achieve even greater positive impacts on the children who enroll. More access problems were found for children with elevated health needs and for those with either low-educated parents or whose primary language is not English. Although these particular groups of children are realizing positive benefits from SCHIP coverage and in some cases, such as children with elevated health care needs, are experiencing even greater reductions in unmet need following SCHIP enrollment relative to other children, they do experience more access problems compared with other SCHIP enrollees.

As hypothesized, the largest impacts were found when the experiences of established enrollees were contrasted with those who were uninsured for the 6 -month period before enrolling. More positive impacts were observed and the magnitude of the impacts was larger when the comparison group was defined as children who had been uninsured for the entire 6-month period before enrolling. Thus, SCHIP should have larger positive effects on children's access to care, other things equal, for the SCHIP enrollees who would have been uninsured otherwise.

Although there were fewer statistically significant differences and the differences were weaker, SCHIP enrollees seemed to have better experiences in some areas compared with the children who had had private coverage for the 6 -month period before enrolling. In particular, they were more likely to have a usual source for dental care, and their parents expressed more confidence and fewer financial difficulties associated with meeting their children's health care needs. These positive effects may reflect higher out-of-pocket spending under private plans relative to SCHIP or disruptions in coverage experienced by these families before enrolling. The fact that children who were enrolled in private coverage were more likely than established enrollees to receive well-child and physician visits but also more likely to have emergency room visits bears further study.

This analysis demonstrates that SCHIP coverage is producing the positive results for children and their families sought by policy makers and program administrators. Additional analysis is needed to assess the quality of the 
care that children are receiving and the impacts that such care maybe having on the health and functioning of children. However, the bottom line from this analysis is that a very diverse set of SCHIP programs, serving different types of enrollees, in different health care environments, is improving access to care for the children who enroll and that improvements are experienced for children with varying socioeconomic backgrounds and health care needs.

\section{ACKNOWLEDGMENTS}

This research was conducted under a congressionally mandated SCHIP evaluation for the United States Department of Health and Human Services Assistant Secretary for Planning and Evaluation. The author gratefully appreciates the comments and suggestions of Jennifer Babcock, Lisa Dubay, Jamie Rubenstein, Rob Stewart, Christopher Trenholm, Judith Wooldridge, and Stephen Zuckerman; and the research assistance of Justin Yee.

Disclaimers: All the opinions expressed in the manuscript are those of the author and do not reflect those of the Urban Institute, the Department of Health and Human Services, or their funders.

\section{NOTES}

1. California, Florida, and New York had combination programs with relatively very small Medicaid components, at the time of the survey.

2. Thus, linguistically isolated families who could not be interviewed in English or Spanish may not be represented in this study.

3. Enrollees who had been enrolled for between 3 and 5 months were excluded from the sample frame, as too much time would have passed since their enrollment to recall their preenrollment experience with a high degree of reliability and they would not have been enrolled in the program for sufficient time to acquire experience with the program.

4. The majority of the recent enrollees reported on their access and use experiences while on SCHIP (instead of the period before enrolling) because the family did not recognize that the child was newly enrolled in SCHIP (due to a seamless transfer from Title XIX) or because there was a significant gap between the time of sampling and the point at which the interview was conducted. There were only small differences in the observed characteristics of the recent enrollee sample used in the impact analysis and the entire sample of recent enrollees. For a full explanation of the classification of recent enrollees and their characteristics, see Trenholm et al. (2005). 
5. A child is defined as having elevated health needs if the child is in fair or poor health or if the child meets one of the following criteria: (1) has an impairment or health problem lasting at least 12 months that limits his/her ability to crawl, walk, run, or play; (2) a health professional has said that the child had asthma or the child has been taking prescribed medication or required injections for his/her asthma; (3) has taken medication or required injections for at least three months; (4) a health professional has said the child had a mental health condition or behavioral problem or the child has a behavioral problem that limits his/her ability to do regular school work or to participate in the usual kind of activities done by most children of his/her age. This measure has not been validated which is a limitation of this study; however, it is similar in many respects to measures that have been validated.

6. Of the group with some coverage in the six months before SCHIP enrollment, 65 percent had some type of insurance coverage (either private or public) for all of the six months before enrolling and 35 percent were uninsured for a portion of the sixmonth period.

7. For established enrollees, the reference period is the six months before the survey, and for recent enrollees the reference period is the six months before the child's enrollment in SCHIP.

8. All the estimates presented are based on linear probability models. Logistic models were also estimated to take into account the discrete nature of the outcomes. These models produced results that are almost identical to the linear probability models with respect to the direction and significance of the impact estimates.

9. Established enrollees are more likely than recent enrollees who had private coverage to have a usual source of dental care and more likely to have parents who feel confident that their children's health care needs will be met and less likely to have parents who feel stress, worry, and financial burden associated with meeting their child's health care needs. It is possible that estimated impacts on confidence, worry, and stress are overstated for this particular population, as they may have experienced disruptions such as job loss that led them to enroll their child in SCHIP. The findings with respect to service use are mixed: established enrollees are less likely to have had a checkup and a physician visit but are also less likely to have an emergency room visit relative to the children who had private coverage before enrolling.

\section{REFERENCES}

Campbell, D. T., and J. C. Stanley. 1963. Experimental and Quasi-Experimental Designs for Research. Boston: Houghton Mifflin Company.

Currie, J., and D. Thomas. 1995. "Medical Care for Children: Public Insurance, Private Insurance and Racial Differences in Utilization.” Journal of Human Resources 30 (1): 135-63.

Damiano, P. C., J. C. Willard, E. T. Momany, and M. A. Tyler. 2002. "HAWK-I: Impact on Access and Health Status." Second Evaluation Report to the Board of 
Directors of the Healthy and Well Kids in Iowa Programs. University of Iowa: Health Policy Research Program, Public Policy Center.

Dick, A. W., C. Brach, R. A. Allison, E. Shenkman, L. P. Shone, P. G. Szilagyi, J. D. Klein, and E. M. Lewit. 2004. "SCHIP's Impact in Three States: How Do the Most Vulnerable Children Fare?" Health Affairs 23 (5): 63-75.

Dubay, L. C., and G. M. Kenney. 2001. "Health Care Access and Use among LowIncome Children: Who Fares Best?" Health Affairs 16 (1): 112-21.

Fox, H. B., R. G. Levtov, and M. A. McManus. 2003. Eligibility, Benefits, and Cost-sharing in Separate SCHIP Programs. Washington, DC: Maternal and Child Health Policy Research Center.

Garber, A. M., and C. E. Phelps. 1997. "Economic Foundations of Cost-Effectiveness Analysis." Journal of Health Economics 16 (1): 1-31.

Grossman, M. 1972. "On the Concept of Health Capital and the Demand for Health." Journal of Political Economy 80 (2): 223-55.

Hill, B. Courtot, and J. Sullivan. 2005. "Ebbing and Flowing: Some Gains, Some Losses as SCHIP Responds to Third Year of Budget Pressure." Assessing the New Federalism Policy Brief A-68. Washington DC: Urban Institute.

Hill, I., C. Hawkes, and M. Harrington. 2003. "Congressionally Mandated Evaluation of the State Children's Health Insurance Program: Final Cross-Cutting Report on the Findings from Ten State Site Visits." Submitted to the Office of the Assistant Secretary for Planning and Evaluation. Washington, DC: U.S. Department of Health and Human Services.

Kaestner, R. 1999. "Health Insurance, the Quantity and Quality of Prenatal Care and Infant Health." Inquiry 36 (2): 162-75.

Kempe, A., B. Beaty, L. A. Crane, J. Stokstad, J. Barrow, S. Belman, and J. F. Steiner. 2005. "Changes in Access, Utilization, and Quality of Care after Enrollment Into a State Child Health Insurance Plan." Pediatrics 115 (2): 364-71.

Kenney, G., and D. Chang. 2004. "The State Children's Health Insurance Program: Success, Shortcomings, and Challenges." Health Affairs 23 (5): 51-62.

Kenney, G., C. Trenholm, L. Dubay, M. Kim, L. Moreno, J. Rubenstein, A. Sommers, and S. Zuckerman. 2005. "The Experiences of SCHIP Enrollees and Disenrollees in Ten States: Findings from the Congressionally Mandated SCHIP Evaluation." Submitted to the Office of the Assistant Secretary for Planning and Evaluation. Washington, DC: U.S. Department of Health and Human Services

Lave, J., C. R. Keane, C. J. Lin, E. M. Ricci, G. Amersbach, and C. P. LaVallee. 1998. "Impact of a Children's Health Insurance Program on Newly Enrolled Children." Journal of the American Medical Association 279 (22): 1820-5.

McBroome, K., P. C. Damiano, and J. C. Willard. 2005. "Impact of the Iowa S-SCHIP Program on Access to Dental Care for Adolescents." Pediatric Dentistry 27 (1): 47-53.

Monheit, A. C., and P. J. Cunningham. 1992. "Children without Health Insurance." Future of Children 2 (2): 154-70.

Moreno, L., and S. Hoag. 2001. "Covering the Uninsured through TennCare: Does It Make a Difference?” Health Affairs 20 (1): 231-9. 
Newacheck, P. W., D. C. Hughes, and J.J. Stoddard. 1996. "Children's Access to Care: Differences by Race, Income, and Insurance Status." Pediatrics 97 (1): 26-32.

Rosenbach, M. L. 1989. "The Impact of Medicaid on Physician Use by Low-Income Children.” American Journal of Public Health 79 (9): 1220-6.

Shone, L. P., A. W. Dick, J. D. Klein, J. Zwanziger, and P. G. Szilagyi. 2005. "Reduction in Racial and Ethnic Disparities after Enrollment in the State Children's Health Insurance Program.” Pediatrics 115 (6): e697-705.

Singleton, R. A., B. C. Straits, and M. M. Straits. 1993. Approaches to Social Research. New York: Oxford University Press.

Slifkin, R. T., F. Freeman, P. Silberman, and R. Schwartz. 2001. Assessing the Effects of the North Carolina Health Choice Program on Beneficiary Access to Care. Chapel Hill, NC: University of North Carolina at Chapel Hill, Cecil G. Sheps Center for Health Services Research.

Smith, V. K., and D. M. Rousseau. 2005. SCHIP Enrollment in 50 States: December 2004 Data Update. Washington, DC: Kaiser Commission on Medicaid and the Uninsured.

Stoddard, J.J., R. F. St.Peter, and P. W. Newacheck. 1994. "Health Insurance Status and Ambulatory Care for Children." New England Journal of Medicine 330 (20): 1421-5. Szilagyi, P. G., J. Zwanziger, L. E. Rodewald, J. L. Hall, D. B. Mukamel, S. Trafton, L. P. Shone, A. W. Dick, L. Jarrell, and R. F. Raubertas. 2000. "Evaluation of a State Health Insurance Program for Low-Income Children: Implications for State Child Health Insurance Programs." Pediatrics 105 (2): 363-71.

Szilagyi, P. G., A. W. Dick, J. D. Klein, L. P. Shone, J. Zwanziger, and T. McInerny. 2004. "Improved Access and Quality of Care after Enrollment in the New York State Children's Health Insurance Program (SCHIP).” Pediatrics 113 (5): e395-404.

Szilagyi, P. G., A. W. Dick, J. D. Klein, L. P. Shone, J. Zwanziger, A. Bajorska, and H. L. Yoos. 2006. "Improved Asthma Care after Enrollment in the State Children's Health Insurance Program in New York.” Pediatrics 117 (2): 486-96.

Trenholm, C., G. Kenney, W. van Kammen, L. Dubay, F. Potter, J. Rubenstein, M. Kim, A. Sommers, L. Moreno, S. Zuckerman, B. Schiff, F. Blavin, W. Black, and G. Ko. 2005. The Experiences of SCHIP Enrollees and Disenrollees in 10 States: Findings from the Congressionally Mandated SCHIP Evaluation: Appendixes. Princeton, NJ: Mathematica Policy Research Inc.

Trude, Sally. 2004. Patient Cost-Sharing: How Much Is Too Much? Washington, DC: Center for Studying Health System Change.

\section{SUPPLEMENTARY MATERIAL}

The following supplementary material for this article is available:

Table A1: Multivariate Estimates of Access and Use Impacts of SCHIP Enrollment: Percentage Difference between Established SCHIP Enrollees Compared to All Recent Enrollees, by State

Table A2: Multivariate Estimates of Access and Use Impacts of SCHIP Enrollment: Percentage Difference between Established SCHIP Enrollees 
Compared to Recent Enrollees Uninsured for the 6 Months Prior to Enrolling, by State

Table A3: Multivariate Estimates of Access and Use Impacts of SCHIP Enrollment: Sensitivity Analyses for All Recent Enrollees

Table A4: Multivariate Estimates of Access and Use Impacts of SCHIP Enrollment: Sensitivity Analyses for Recent Enrollees Uninsured for the 6 Months before Enrolling

Table A5: Multivariate Estimates of Access and Use Impacts of SCHIP Enrollment: Sensitivity Analyses for Recent Enrollees Insured for Some or Part of the Previous 6 Months before Enrolling

Table A6: Multivariate Estimates of Access and Use Impacts of SCHIP Enrollment: Access and Use Impacts of SCHIP Enrollment Relative to Being Uninsured for the 6 Months before Enrolling, by Subgroup

Table A7: Multivariate Estimates of Access and Use Impacts of SCHIP Enrollment: Differential Impacts of SCHIP Enrollment Relative to Being Uninsured All 6 Months before Enrolling, by Subgroup

This material is available as part of the online article from http:// www.blackwell-synergy.com/doi/abs/10.1111/j.1475-6773.2007.00707.x (this link will take you to the article abstract).

Please note: Blackwell Publishing is not responsible for the content or functionality of any supplementary materials supplied by the authors. Any queries (other than missing material) should be directed to the corresponding author for the article. 